\title{
Optimal design of underground gas storage
}

\author{
S. Kravanja \& B. Žlender \\ University of Maribor, Faculty of Civil Engineering, Slovenia
}

\begin{abstract}
This paper presents the cost optimization of an underground gas storage (UGS), designed from lined rock caverns (LRCs). The optimization is performed by the non-linear programming (NLP) approach. For this purpose, the NLP optimization model OPTUGS was developed. The model comprises the cost objective function, which is subjected to geomechanical and design constraints. It is proposed that the geotechnical problem will be solved simultaneously. In such a way, the optimization enables not only that the solution is optimal, but also that the rock mass achieves enough strength, stability and safety. It is proposed that the optimization will be performed for the phase of the conceptual design. The numerical example at the end of the paper demonstrates the efficiency of the introduced optimization approach.
\end{abstract}

Keywords: underground gas storage, UGS, lined rock cavern, LRC, optimization, non-linear programming, NLP.

\section{Introduction}

The paper deals with the optimization of the investment and operational costs of an underground gas storage (UGS), designed from lined rock caverns (LRCs) [1-3]. The optimization is performed by the non-linear programming (NLP) approach. For this purpose, the NLP optimization model is developed. Since the optimization is proposed to be performed for the phase of the conceptual design, only some basic conditions are defined in the optimization model in order to assure enough strength safety of the rock mass and impermeability of the cavern wall and steel lining. The latter is achieved by the limitation of steel lining and concrete wall stains.

The considered UGS is performed by the construction of one or more LRCs. The structure of the LRC is simple: its reservoir wall is designed from a concrete wall and a steel lining. Although the concrete wall is reinforced, it just transports 


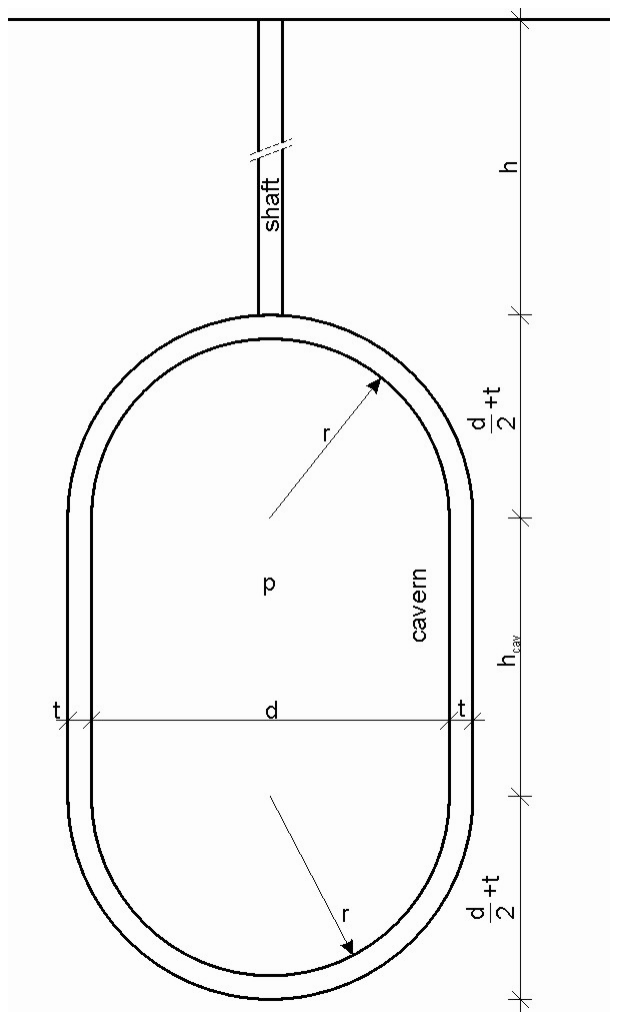

Figure 1: $\quad$ Vertical cross-section of the lined rock cavern (LRC).

the gas pressure from the cavern on the surrounding rock. The same holds with the steel lining, which only enables the impermeability (sealing) of the cavern.

The primary objectives of the proposed optimization of the investment and operational costs of the UGS are:

- Minimization of the investment and operational costs of the UGS system,

- Storing the highest possible quantity of gas under high pressure,

- Ensure the safety of the UGS at the time of construction and service,

- Calculation of the optimal inner gas pressure, the cavern depth, the cavern inner diameter, thickness of the cavern concrete wall and the height of the cavern tube through the optimization.

In order to achieve the upper objectives, it is proposed that the geotechnical problem will be solved simultaneously. Geomechanical rock mass parameters are determined from geological conditions of a selected suitable UGS location and a special FE model is generated. Strength stability of the rock mass and safety of the system are then analyzed for various design parameters like the inner gas pressures, cavern depths, cavern diameters and the cavern wall thickness. As a result, geomechanical constraints are proposed to be approximated/defined and put into the optimization model. 


\section{Underground gas storage designed from LRC}

The design of the considered LRC structure is typical, see Figure 1. The LRC consists from the cylindrical wall and the upper and lower spheres. The caverns are typically 50 to $100 \mathrm{~m}$ high and are located at depths from 100 to $300 \mathrm{~m}$. Their concept involves relatively large diameters: between 10 and $50 \mathrm{~m}$. The concrete wall is 2 or more meters thick, the thickness of the steel lining amounts from 12 to $15 \mathrm{~mm}$.

It is expected that the gas pressure cyclically increases and decreases during periods of gas supply and discharge between the minimal ( $3 \mathrm{MPa}$ ) and maximal (calculated) value. The internal pressure therefore causes static and cyclic loads. The minimum lifetime of the LRC is limited to be higher than 500 cycles. Since caverns are constructed at the depths between 100 and $300 \mathrm{~m}$, the hydrostatic pressure reaches 1 to $3 \mathrm{MPa}$. Drainage system is installed on the outer side of the cavern wall. It drainages the water and enables the monitoring, collection and removing of the gas in the case of gas leakage.

The system of tunnels is designed in order to transport material and allow the access for machinery during the construction of the underground chambers. The tunnels also provide a cost-effective mining of caverns. Cross-section of tunnels amounts about $25 \mathrm{~m}^{2}$ in the flat areas and $40 \mathrm{~m}^{2}$ in curved areas.

The risks that occur during the construction are similar to ones at the construction of tunnels: large-scale failure of the rock cover, large deformations of the cavern wall, irruption of the water and impact on water resources in the surrounding area. The risks that may occur during the operation are: failure of the rock mass, uplift of the rock cover, failure of the rock between two caverns, large deformation or destruction of the steel lining, unequally deformation of the LRC structure because of the rock heterogeneity and the draining system does not work. Since the risks during the operation are decisive, the risks during the construction are not considered explicitly in this paper.

The LRC concept should provide a safe and environmentally friendly mode for gas storage. Since the gas should never been in contact with the environment, the gas storage is designed as a closed system. The caverns and the entire gas network are impermeable.

\section{Optimization model OPTUGS}

The general optimization model OPTUGS was developed for the optimization of the underground gas storage. As the optimization problem of the UGS is nonlinear, the non-linear programming (NLP) optimization approach is used and described in the paper.

\subsection{NLP problem formulation}

The general NLP optimization problem can be formulated as follows:

$$
\min z=f(\boldsymbol{x})
$$




$$
\begin{gathered}
\text { subjected to: } \\
\boldsymbol{h}(\boldsymbol{x})=\mathbf{0} \\
\boldsymbol{g}(\boldsymbol{x}) \leq \mathbf{0} \\
\boldsymbol{x} \in X=\left\{\boldsymbol{x} \mid \boldsymbol{x} \in R^{n}, \boldsymbol{x}^{L o} \leq \boldsymbol{x} \leq \boldsymbol{x}^{U p}\right\}
\end{gathered}
$$

where $\boldsymbol{x}$ is a vector of continuous variables, defined within the compact set $X$. Functions $f(\boldsymbol{x}), \boldsymbol{h}(\boldsymbol{x})$ and $\boldsymbol{g}(\boldsymbol{x})$ are nonlinear functions involved in the objective function $z$, equality and inequality constraints, respectively. All functions $f(\boldsymbol{x})$, $\boldsymbol{h}(\boldsymbol{x})$ and $\boldsymbol{g}(\boldsymbol{x})$ must be continuous and differentiable.

In the context of structural optimization, variables include dimensions, crosssection characteristics, strains, materials, stresses, economic parameters, etc. Equality and inequality constraints and the bounds of the variables represent a rigorous system of the design, loading, stress, resistance and deflections functions taken from structural analysis and the dimensioning.

\subsection{NLP optimization model}

According to the above NLP problem formulation, an NLP optimization model OPTUGS was developed. As an interface for mathematical modeling and data inputs/outputs GAMS (General Algebraic Modeling System), a high-level language [4], was used. The proposed optimization model includes input data (constants), variables and cost objective function of the UGS system, subjected to defined geomechanical and design non-linear and linear constraints.

Input data represent design and economical data (constants) for the optimization. Coefficients involved in the objective function and geomechanical inequality constraints are also defined as input data.

The inner gas pressure $p[\mathrm{MPa}]$, the cavern depth $h[\mathrm{~m}]$, the cavern inner diameter $d[\mathrm{~m}]$, the cavern concrete wall thickness $t[\mathrm{~m}]$ and height of the cavern tube $h_{\text {cav }}[\mathrm{m}]$ are in the optimization model OPTUGS declared as variables, see Figure 1.

\subsubsection{Objective function}

The objective function comprises the investment and operational costs of the UGS system COSTS [EUR], see eqn. (1).

$$
\operatorname{COSTS}=\left\{\begin{array}{l}
\cos t_{u p}+\cos t s_{\text {under }} \\
+C_{e x c, t u n} \cdot V_{e x c, t u n}^{s f}+C_{p r o t, t u n} \cdot V_{e x c, t u n}^{s f} \\
+C_{e x c, c a v} \cdot V_{e x c, c a v}^{s f} \\
+C_{p r o t, c a v} \cdot A_{e x c, c a v}^{s f}+C_{d r a i n} \cdot A_{e x c, c a v}^{s f} \\
+C_{\text {wall }} \cdot\left(V_{e x c, c a v}^{s f}-V_{c a v}^{s f}\right)+C_{r e i n f} \cdot\left(V_{e x c, c a v}^{s f}-V_{c a v}^{s f}\right) \cdot \rho \cdot r_{p e r c} \\
+C_{s t e e l} \cdot A_{c a v}^{s f}
\end{array}\right\} \cdot N o_{c a v}
$$


The objective variable COSTS includes fixed costs (constant sum) and dimension dependence (variable) costs. The fixed costs amounts upper ground works $\operatorname{costs}_{u p}$ [EUR] and underground works costs $_{\text {under }}$ [EUR].

The dimension dependence costs are dependent on a depth of the tunnel excavation, structure and protection, on a geometry of the cavern excavation, protection and drainage system as well as on used quantities of the cavern concrete, the reinforcement and steel lining. In this way, the tunnel excavation and protection costs are determined by the term $C_{\text {exc, tun }} \cdot V^{\Delta f}$ exc, tun $+C_{\text {prot,tun }} \cdot V^{\text {sf }}{ }_{\text {exc, tun }}$, where $C_{\text {exc,tun }}\left[\mathrm{EUR} / \mathrm{m}^{3}\right]$ represents the price of the tunnel excavation, $C_{\text {prot,tun }}$ $\left[E U R / \mathrm{m}^{3}\right]$ is the price of the tunnel protection and $V^{s f}{ }_{e x c, t u n}\left[\mathrm{~m}^{3}\right]$ denotes a volume of vertical and horizontal tunnel excavation. Coefficient $s_{\text {exc }}$ varies from the case to case and is dependent on the number of LRCs inside the UGS. The cavern excavation costs $C_{\text {exc,cav }} \cdot V^{\text {sf }}{ }_{\text {exc,cav }}$ are defined with the price of the cavern excavation $C_{\text {exc,cav }}\left[\mathrm{EUR} / \mathrm{m}^{3}\right]$ and the cavern excavation volume $V^{s f}$ exc,cav $\left[\mathrm{m}^{3}\right] . \mathrm{In}$ addition, the cavern protection and drainage system costs are expressed by the expression $C_{\text {prot,cav }} \cdot A^{s f}{ }_{\text {exc,cav }}+C_{\text {drain }} \cdot A_{\text {exc,cav }}^{\text {sf }}$, where $C_{\text {prot,cav }}\left[\mathrm{EUR} / \mathrm{m}^{2}\right]$ represents the price of the cavern protection, $C_{\text {drain }}\left[\mathrm{EUR} / \mathrm{m}^{2}\right]$ stands for the price of the cavern drainage and $A_{\text {exc,cav }}^{s f}\left[\mathrm{~m}^{2}\right]$ is the cavern excavation area. Costs of the concrete for walls are calculated by the expression $C_{\text {wall }}\left(V^{s f}{ }_{\text {exc,cav }} V^{s f} f_{c a v}\right)$, where $C_{\text {wall }}\left[\mathrm{EUR} / \mathrm{m}^{3}\right]$ represents the price of the cavern wall concrete, the term $\left(V^{s f}{ }_{e x c, c a v}-V_{c a v}^{s f}\right)$ denotes the volume of used concrete, $V^{s f}$ cav stands for the inner volume of the cavern. Costs for the reinforcements are defined by the term $C_{\text {reinf }}\left(V_{\text {exc,cav }}^{\Delta f} V^{\Delta f}{ }_{c a v}\right) \cdot \rho \cdot r_{\text {perc }}$, where $C_{\text {reinf }}[\mathrm{EUR} / \mathrm{t}]$ is the price for the wall reinforcement, $\rho\left[\mathrm{t} / \mathrm{m}^{3}\right]$ represents the unit mass of steel and $r_{\text {perc }}[-]$ denotes the percentage of the reinforcement. Finally, costs of steel lining are determined by the term $C_{\text {steel }} \cdot A^{s f}$ cav, where $C_{\text {steel }}\left[\mathrm{EUR} / \mathrm{m}^{2}\right]$ represents the price of the steel lining and $A_{c a v}^{s f}$ the spread area of the steel lining (inner cavern area). $N o_{c a v}$ stands for the number of constructed caverns in the UGS system.

\subsubsection{Geomechanical constraints}

Geomechanical inequality constraints enable the rock mass strength stability and safety. In this way, four conditions have to be defined in a form of four geomechanical inequality constraints:

- Condition 1: Strength of the rock mass is not exceeded, eqn. (2),

- Condition 2: Uplift of the rock cover is prevented, eqn. (3),

- Condition 3: Failure of the rock between two caverns is prevented, eqn. (4),

- Condition 4: Strains of the steel lining need to be limited under the acceptable value, eqn. (5).

Condition 1 is checked by eqn. (2), by which the design gas pressure $p$ [MPa] must not exceed the limit gas pressure $p_{G S I}$, calculated by Noren criterion [5]. While parameter GSI has to be evaluated for the each UGS system separately by the generalized Hoek-Brown failure criterion [6], parameter $a$ is 0.004 and parameter $b$ is 2.190 .

$$
p \leq p_{G S I}^{s f}
$$


where:

$$
p_{G S I}^{s f}=a_{\mathrm{N}} \cdot G S I^{b_{N}}
$$

Condition 2 is satisfied when the calculated safety factor against the rock cover uplift $S F_{u p}$ is greater than a defined minimal value $S F_{u p, m i n}$, see Eq. (3). A typical value for $S F_{u p, \min }$ is taken as 3 .

$$
S F_{u p}^{s f} \geq S F_{u p, \min }
$$

where $S F_{u p}^{s f}$ is a following substitution function:

$$
S F_{u p}^{s f}=S F_{u p, 0} \cdot c_{1} \cdot\left(\frac{p}{p_{0}}\right)^{f_{1}} \cdot c_{2} \cdot\left(\frac{h}{h_{0}}\right)^{f_{2}} \cdot c_{3} \cdot\left(\frac{d}{d_{0}}\right)^{f_{3}}
$$

When Condition 3 is considered, the calculated safety factor against the rock failure between two caverns $S F_{\text {horiz }}$ must be greater than a defined minimal value $S F_{\text {horiz,min }}$, see Eq. (4). A typical value for $S F_{\text {horiz,min }}$ is 2.5 .

$$
S F_{\text {horiz }}^{s f} \geq S F_{\text {horiz,min }}
$$

where $S F_{\text {horiz }}^{s f}$ is:

$$
S F_{\text {horiz }}^{s f}=S F_{\text {horiz }, 0} \cdot g_{1} \cdot\left(\frac{p}{p_{0}}\right)^{i_{1}} \cdot g_{2} \cdot\left(\frac{h}{h_{0}}\right)^{i_{2}} \cdot g_{3} \cdot\left(\frac{d}{d_{0}}\right)^{i_{3}}
$$

When Condition 4 is checked, strains of steel lining $\varepsilon$ are limited to be smaller than a defined maximal strain $\varepsilon_{\max }$, see Eq. (5). For a typical number of 1000 cycles of cavern loading $\varepsilon_{\max }$ is $3.5 \%$.

$$
\varepsilon^{s f} \leq \varepsilon_{\max }
$$

where $\varepsilon^{s f}$ is:

$$
\varepsilon^{s f}=\varepsilon_{0} \cdot j_{1} \cdot\left(\frac{p}{p_{0}}\right)^{k_{1}} \cdot j_{2} \cdot\left(\frac{h}{h_{0}}\right)^{k_{2}} \cdot j_{3} \cdot e^{k_{s} \cdot\left(\frac{t / d}{t_{0} / d_{0}}\right)}
$$

While $p[\mathrm{MPa}]$ represents inner gas pressure, $h[\mathrm{~m}]$ is the cavern depth, $d[\mathrm{~m}]$ stands for the cavern inner diameter and $t[\mathrm{~m}]$ is thickness of the concrete wall; constants $p_{0}, h_{0}, d_{0}, t_{0}$, and $l_{0}$ represent the initial values of mentioned parameters.

It should be noted that it is proposed that the substituted functions, i.e. eqns. (3.1), (4.1) and (5.1), are approximated from a series of FEM analyses for the particular UGS system and its geomechanical parameters (see the numerical example at the end of the paper).

\subsubsection{Design (in)equality constraints}

Design (in)equality constraints determine the UGS cavern geometry and the gas pressure to be calculated inside the defined limits. The reliability of the system 
depends on several geometrical parameters such as the depth and diameter of the cavern, and its height. Thickness of the cavern wall also plays an important role. Relation between the cavern volume, the design stored gas capacity and gas pressure should also be defined. Gas pressure $p$ is calculated by the constraint (6).

$$
10 \leq p \leq 30
$$

Depth of the cavern $h[\mathrm{~m}]$ is bounded, see eqn. (7).

$$
100 \leq h \leq 300
$$

The cavern inner diameter $d[\mathrm{~m}]$ varies between its lower and upper bounds, see eqn. (8).

$$
10 \leq d \leq 30
$$

Constraint (9) defines bounds of the concrete wall thickness $t$ [m].

$$
2 \leq t \leq 5
$$

The height of the cavern tube $h_{c a v}[\mathrm{~m}]$ is defined by eqn. (10).

$$
0 \leq h_{c a v} \leq 30
$$

Relation between the cavern volume $V_{c a v}^{s f}$, the stored gas capacity $V_{\text {gas }}$ and the gas pressure $p$ is given by eqn. (11).

$$
V_{c a v}^{s f}=\frac{V_{\text {gas }}}{13,246 \cdot p-0,073 \cdot p^{2}}
$$

\section{Numerical example}

In order to interpret the proposed optimization approach, the paper presents a study of the NLP optimization of the investment and operational costs of an underground gas storage, planned in Senovo [7, 8], located in the south-eastern part of Slovenia. It is planned to construct the UGS from a single lined rock cavern in order to store 5.56 million $\mathrm{m}^{3}$ of natural gas. The concrete C 30/37 and structural steel S 235 are used for the construction of tunnels, cavern walls and steel lining. Steel S 400 was used for the reinforcement. Steel lining is $12 \mathrm{~mm}$ thick. The optimization/calculation of the UGS system comprises:

- Determination of the rock mass parameters for the location of Senovo,

- Definition of the geomechanical inequality constraints for the treated UGS,

- Optimization of the UGS system Senovo.

\subsection{Determination of the rock mass parameters}

Data obtained from geological mapping and the geological inventory of the core wells, confirming act and limestone dolomites in the eastern area of mine Senovo, are presented in reference [7]. After all needed geological data were 
obtained, rock mass parameters were determined on the basis of the generalized Hoek-Brown failure criterion [6, 9]. The computer program RocLab was applied [10]. The geological strength index GSI was 46. The Mohr-Coulomb strength parameters are derived, i.e. the cohesion $c$ was $900 \mathrm{kPa}$ and the friction angle $\varphi$ was $39^{\circ}$. Finally, calculated were the rock mass parameters: the rock mass tensile strength $\sigma_{t}$ was $0.092 \mathrm{MPa}$, the uniaxial rock mass compressive strength $\sigma_{c}$ was $2.29 \mathrm{MPa}$, the global rock mass compressive strength $\sigma_{c m}$ was $8.13 \mathrm{MPa}$ and the rock mass deformation modulus $E_{r m}$ was $10.70 \mathrm{GPa}$.

\subsection{Definition of the geomechanical inequality constraints}

After the rock mass parameters were determined, the calculation was followed by the development of the geomechanical inequality constraints for the location of Senovo. When Conditions 1, 2 and 3 (strength, uplift and failure of the rock) where checked, the rock mass was treated as discontinuous, having enough shear strength. On the other hand, when strains of the steel lining were calculated (Condition 4), the rock mass was treated as a continuum with uniform conditions over the circumference of LRC. It was assumed that the concrete cracks are small and enable to transfer the load on the rock mass.

While Eq. (2) was in point of fact already defined because the GSI parameter was determined as mentioned in Section 4.1, other geomechanical constraints, i.e. eqn. (3)-(5) with all coefficients had still to be evaluated. For this purpose, a 3-D FE model of the UGS system and the surrounding rock mass area was generated. The FE mesh, consisted from triangle prismatic finite elements, was defined for a space area of $280 \times 280 \times 300 \mathrm{~m}^{3}$ (x-y-z, with $\mathrm{z}$ the axis in depth). The FEM computer program Plaxis Version 3D [11] was used. A series of FEM analyses for the treated UGS of Senovo were performed. In this way, safety factors against the rock cover uplift $S F_{u p}$ and the rock failure between two caverns $S F_{\text {horiz }}$ as well as strains of steel lining $\varepsilon$ were calculated for various combinations between different inner gas pressures, cavern depths, cavern diameters and the cavern wall thickness. As a result, geomechanical functions/constraints and their coefficients were finally approximated and put into the optimization model OPTUGS, see Table 1.

Table 1: $\quad$ Evaluated coefficients for geomechanical function eqns. (3.1), (4.1) and (5.1).

\begin{tabular}{|c|c|c|}
\hline$S F^{s f}{ }_{u p}$ eqn. (3.1) & $S F^{\text {sf }}$ horiz eqn. (4.1) & $\varepsilon^{s f}$ eqn. (5.1) \\
\hline \multicolumn{2}{|c|}{$p_{0}=20 \mathrm{MPa}, h_{0}=150 \mathrm{~m}, d_{0}=25 \mathrm{~m}, t_{0}=2 \mathrm{~m}$} \\
\hline$S F_{u p, 0}=2.5686$ & $S F_{\text {horiz }, 0}=2.6190$ & $\varepsilon_{0}=4.9300$ \\
\hline$c_{1}=0.9999$ & $g_{1}=0.9946$ & $j_{1}=1.0084$ \\
\hline$f_{1}=-0.9999$ & $i_{1}=-0.9701$ & $k_{1}=1.8511$ \\
\hline$c_{2}=0.9957$ & $g_{2}=0.9990$ & $j_{2}=1.0050$ \\
\hline$f_{2}=1.7159$ & $i_{2}=0.8714$ & $k_{2}=-0.5540$ \\
\hline$c_{3}=0.9979$ & $g_{3}=0.9789$ & $j_{3}=1.1619$ \\
\hline$f_{3}=-1.0610$ & $i_{3}=-0.9410$ & $k_{3}=-0.1481$ \\
\hline
\end{tabular}




\subsection{Optimization of the UGS system}

The optimization of the underground gas storage system in Senovo was performed by the NLP optimization approach. The task of the optimization was to find the minimal possible system's investment and operational costs for the phase of the conceptual design.

The developed optimization model OPTUGS was used. The economic data for the optimization, which were fulfilled into the objective function, are presented in Table 2 . The design stored gas capacity per the cavern $V_{\text {gas }}$ was planned to be 5.56 million $\mathrm{m}^{3}$, number of planned caverns $N o_{c a v}$ was 1 , the volume of tunnel excavation per cavern $s_{\text {exc }}$ was $1330 \mathrm{~m}^{3}$, the unit mass of steel $\rho$ was $7.85 \mathrm{t} / \mathrm{m}^{3}$ and the percentage of the reinforcement $r_{\text {perc }}$ was $0.15 \%$.

Since the NLP model OPTUGS is highly non-linear, the optimization was performed by the computer code GAMS/CONOPT2 (the general reduced gradient method) [12]. The optimal result represented the obtained UGS system's minimal investment and operational costs of 32.807 millions EUR or 5.90 EUR per $\mathrm{m}^{3}$ of stored gas. The solution also comprised the calculated optimal inner gas pressure $p=17.46 \mathrm{MPa}$, the cavern depth $h=190.12 \mathrm{~m}$, the cavern inner diameter $d=30.00 \mathrm{~m}$, thickness of the cavern concrete wall $t=2.00 \mathrm{~m}$ and the height of the cavern tube $h_{c a v}=17.63 \mathrm{~m}$, see Figure 2 .

Since the investment and operational costs of the primal non-optimized project amounted 9.00 EUR per $\mathrm{m}^{3}$ of stored gas, the proposed optimization decreased the costs for $34.44 \%$. The optimal solution also enabled the rock mass strength stability and the system's safety.

\section{Conclusions}

The paper presents the optimization of the investment and operational costs of underground gas storages (UGS) designed from lined rock caverns (LRC). The optimization is performed by the non-linear programming (NLP) approach. For this purpose, the NLP optimization model OPTUGS was developed. The model comprises the cost objective function, which is subjected to geomechanical and

Table 2: $\quad$ Economic data for the optimization.

\begin{tabular}{|c|c|c|c|}
\hline costs $_{\text {up }}$ & upper ground works & 10480000 & $\mathrm{EUR}$ \\
\hline costs $_{\text {under }}$ & underground works & 6048025 & $\mathrm{EUR}$ \\
\hline$C_{\text {exc,tun }}$ & price of the tunnel excavation & 2440 & $\mathrm{EUR} / \mathrm{m}^{3}$ \\
\hline$C_{\text {prot,tun }}$ & price of the tunnel protection & 1340 & $\mathrm{EUR} / \mathrm{m}^{3}$ \\
\hline$C_{\text {exc.cav }}$ & price of the cavern excavation & 100 & $\mathrm{EUR} / \mathrm{m}^{3}$ \\
\hline$C_{\text {prot,cav }}$ & price of the cavern protection & 90 & $\mathrm{EUR} / \mathrm{m}^{2}$ \\
\hline$C_{\text {drain }}$ & price of the cavern drainage & 60 & $\mathrm{EUR} / \mathrm{m}^{2}$ \\
\hline$C_{\text {wall }}$ & price of the cavern wall concrete & 190 & $\mathrm{EUR} / \mathrm{m}^{3}$ \\
\hline$C_{\text {reinf }}$ & price for the wall reinforcement & 2000 & $\mathrm{EUR} / \mathrm{t}$ \\
\hline$C_{\text {steel }}$ & price of the steel lining & 920 & $\mathrm{EUR} / \mathrm{m}^{2}$ \\
\hline
\end{tabular}




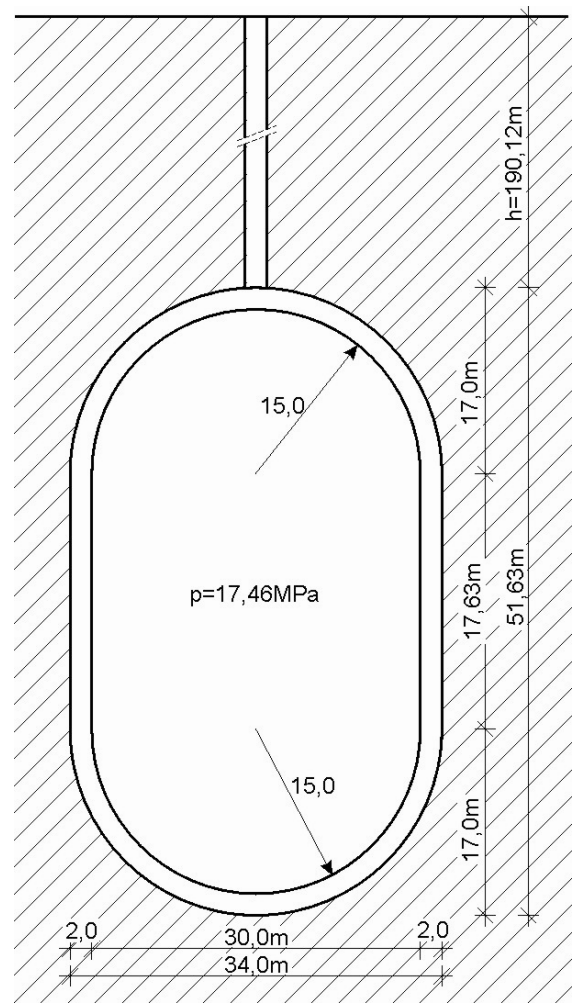

Figure 2: Optimal design of the cavern, UGS Senovo.

design constraints. As the model was developed in a general form, the optimization of the system can be performed for different economic conditions, different number of LRCs, and various gas capacities as well as for different rock environments. It is proposed to perform the optimization for the phase of the conceptual design.

A study of the optimization of investment and operational costs of an underground gas storage is presented at the end of the paper. The obtained result shows that the optimization enables $34.44 \%$ of savings in investment costs when compared to the primal design obtained by the classical method. The optimal solution also enables the rock mass strength stability and the system's safety.

\section{References}

[1] Sofregaz, U.S., Commercial potential of natural gas storage in lined rock caverns (LRC), U.S. Department of Energy, 1999.

[2] Brandshaug, T., Christianson, M., Damjanac, B., U.S., Department of Energy: Technical Review of the Lined Rock Cavern (LRC) - Concept and 
Design Methodology: mechanical Response of Rock Mass, U.S. Department of Energy, 2001.

[3] Chung, I.M, Chob, W., Heob J.H., Stochastic hydraulic safety factor for gas containment in underground storage caverns. Journal of Hydrology, 284, pp.77-91, 2003.

[4] Brooke, A., Kendrick, D. and Meeraus, A., GAMS - A User's Guide, Scientific Press, Redwood City, CA, 1988.

[5] Noren, C., Underground Storage of Natural Gas in Lined Rock Cavern in Brestanica Area, NCC, Stockholm, 2006.

[6] Hoek, E., Brown, E.T., Practical Estimates of Rock Mass Strength. International Journal of Rock Mechanics and Mining Sciences, 34 (8), pp. 1165-1186, 1997.

[7] Vukelič, Ž., Sternad, Ž., Vukadin, V., Čadež, F., Hude, M., Pečovnik, I., High Pressure Storage of Gas in Area of Coal Mine Senovo. RMZ Materials and Geoenvironment, 53 (3), pp. 303-313, 2006.

[8] Trauner, L., Škrabl, S., Vrecl Kojc, H., Žlender, B., Geotechnical opinion on feasible high-pressure natural gas storage Zakov/Senovo, 2007.

[9] Hoek, E. and Diederichs, M.S., Empirical estimation of rock mass modulus. International Journal of Rock Mechanics and Mining Sciences, 43, pp. 203-215, 2006.

[10] Hoek, E., Practical Rock Engineering - An Ongoing Set of Notes, available on the website, www.rocscience.com.

[11] Plaxis, http://www.plaxis.nl.

[12] Drudd, A.S., CONOPT - A Large-Scale GRG Code. ORSA Journal on Computing, 6 (2), pp. 207-216, 1994. 